\title{
Evaluation of Mean Crystallite Size on Magnetic Powder by Scanning Electron Microscopy and Synchrotron Diffractometry
}

\author{
Eguiberto Galego, Marilene Morelli Serna, Rubens Nunes de Faria Junior \\ Instituto de Pesquisas Energéticas e Nucleares, IPEN-CNEN, São Paulo, Brazil \\ Email: egalego@ipen.br
}

Received 26 March 2014; revised 4 May 2014; accepted 29 May 2014

Copyright (C) 2014 by authors and Scientific Research Publishing Inc.

This work is licensed under the Creative Commons Attribution International License (CC BY). http://creativecommons.org/licenses/by/4.0/

(c) (i) Open Access

\begin{abstract}
This paper presents the results of investigations carried out with Pr-based magnetic powders. The magnetically hard powders were produced from homogenised alloys using a high temperature hydrogen pulverization process. Alloys and powders were investigated by scanning electron microscopy and by energy dispersive $X$-ray analysis. Mean crystallite size of the pulverized material was estimated using synchrotron powder diffractometry and the Scherrer method. A comparison between these two investigation techniques has been carried out. The effects of copper on the properties of the magnetic powders have been studied. It has been shown that the addition of this alloying element had a marked effect on the microstructure of the powders.
\end{abstract}

\section{Keywords}

Rare Earth Alloys, Magnetic Powders, Hydrides, Synchrotron Radiation

\section{Introduction}

Anisotropic and isotropic magnetic powders have been produced successfully with REFeB-type alloys using hydrogen processing (examples in [1]-[9]). Typical $\mathrm{Nd}_{12.5} \mathrm{Fe}_{76.1} \mathrm{Co}_{5.5} \mathrm{~B}_{5.9}$ bonded magnets have shown remanence $\left(B_{r}\right)$ of $0.62 \mathrm{~T}$ and coercivity $\left.{ }_{i} H_{c}\right)$ of $1.15 \mathrm{~T}$ [3]. In these magnets, addition of $\mathrm{Ga}$ and $\mathrm{Zr}$ resulted in anisotropic powders. Bonded $\mathrm{Nd}_{12.6} \mathrm{Fe}_{69.4} \mathrm{Co}_{11.5} \mathrm{~B}_{6} \mathrm{Ga}_{0.5}$ magnets showed $B_{r}$ values of $0.89 \mathrm{~T}$ and ${ }_{i} H_{c}$ of about $1.33 \mathrm{~T}$ [4]. Addition of $\mathrm{Zr}$ to these materials induced even higher ${ }_{i} H_{c}(1.38 \mathrm{~T})$ [5]. Pr-based powders have also been produced via this process [9]. $B_{r}$ of about $0.67 \mathrm{~T}$ and ${ }_{i} H_{c}$ of $0.69 \mathrm{~T}$ were reported for a $\mathrm{Pr}_{13} \mathrm{Fe}_{81} \mathrm{~B}_{6}$ powder [7]. Additions of $\mathrm{Co}, \mathrm{Nb}$ and $\mathrm{Zr}$ also led to the development of optimum anisotropic magnetic properties in PrFeB-based powders. It has been shown that powders based on the composition $\operatorname{Pr}_{13.7} \mathrm{Fe}_{63.5} \mathrm{Co}_{16.7} \mathrm{~B}_{6} \mathrm{M}_{0.1}(\mathrm{M}=\mathrm{Zr}$ or Nb$)$, with good $B_{r}$ 
and reasonable ${ }_{i} H_{c}(\sim 1 \mathrm{~T})$, can be produced by this process [9]. However, Ga additions to Pr-based bonded magnets induced anisotropy, but with reduced ${ }_{i} H_{c}$. A magnetic powder based on the alloy $\mathrm{Pr}_{13} \mathrm{Fe}_{68.9} \mathrm{Co}_{24} \mathrm{~B}_{6} \mathrm{Ga}_{1} \mathrm{Zr}_{0.1}$ was reported to have $B_{r}$ of $0.98 \mathrm{~T}$ with ${ }_{i} H_{c}$ of only $0.48 \mathrm{~T}$ [8].

A number of variables affect the hydrogen pulverization process [9] and, therefore, it is easier to use processing conditions that have yielded good results in the past and then seek the alloying element that imparts the best properties. The hydrogen treatment used for the Pr-based alloys [9] is very convenient because it uses a moderate temperature and a relatively low hydrogen pressure and finding an alloying element that induces high anisotropy or high ${ }_{i} H_{c}$ is considered to be very important. Copper has always been associated with good magnetic properties in cast and hot-pressed Pr-Fe-B-based permanent magnets [10]. Grain refinement in the cast alloys and improvement of hot-workability have also been attributed to this element [11]. Furthermore, $\mathrm{Cu}$ has induced high ${ }_{i} H_{c}$ in sintered Pr-based magnets [12]. In this study, copper alloying has been used to change the magnetic properties and microstructures of Pr-based materials. The alloys are represented by the formulae: $\mathrm{Pr}_{14} \mathrm{Fe}_{\text {bal }} \mathrm{Co}_{16} \mathrm{~B}_{6} \mathrm{Nb}_{0.1}$ and $\mathrm{Pr}_{14} \mathrm{Fe}_{63.8} \mathrm{Co}_{16} \mathrm{~B}_{6} \mathrm{Nb}_{0.1} \mathrm{Cu}_{0.1}$. These materials were investigated by scanning electron microscopy (SEM) and X-ray diffraction (XRD) using synchrotron radiation. The main advantage of synchrotron diffractometry is the monochromatic radiation with a higher peak definition when compared to conventional XRD. A comparison between these two characterization methods has been carried out. Attempts have also been made to correlate the magnetic properties with the powder microstructures.

\section{Experimental Procedures}

Two commercial alloys were used in this investigation. The chemical analyses of the as-cast alloys are given in Table 1. As per the supplier's specification, the alloys contained neodymium (0.2 - $0.7 \mathrm{wt} \%)$, aluminium (0.02 $0.2 \mathrm{wt} \%)$ and silicon (0.01 - $0.04 \mathrm{wt} \%)$ as impurities. The procedure used to prepare the magnetic powder and bonded magnet has been described in details in a previous work [9]. In this work the powders were isostatically pressed and consolidated by immersion (vacuum impregnated) in low viscosity cyanoacrylate adhesive at $70^{\circ} \mathrm{C}$ to form permanent magnets. Magnetic characterization was carried out using a permeameter (accuracy: 2\%) after saturation in a pulsed field of 6 T. $B_{r}$ values have been normalized assuming $100 \%$ density $\left(7.5 \mathrm{~g} \cdot \mathrm{cm}^{-3}\right)$ for the sample and considering a linear relationship between density and $B_{r}$ [9].

The microstructures of the pulverized material were examined in a (Philips XL 30) scanning electron microscope fitted with energy dispersive X-ray analysis (EDX). Data obtained from analysing three regions $\sim 100 \mu^{2}$ of each phase for count times of $120 \mathrm{~s}$ were averaged to improve detection of $\mathrm{Cu}$ in the matrix phase. Boron could not be analyzed by EDX.

In order to estimate the mean crystallites size of the pulverized material X-ray diffraction was employed. X-ray was yielded in a synchrotron beam with a tuned wavelength of $2.2912 \AA$ by a double-crystal monochromator. The diffractometer used a parallel geometry (slits: $3 \mathrm{~mm}$ for scattering and $1 \mathrm{~mm}$ for receiving) with a 1 $m$ radius goniometer. Measurements of the instrumental widening were carried out employing an $\mathrm{Al}_{2} \mathrm{O}_{3}$ standard. Step-scanning was carried out at a rate of 0.01 degree per step and the time base was normalized to incident beam monitor counts. Hydrogenated samples were crushed with a mortar and pestle in air, such that all the material passed through a $\leq 48 \mu \mathrm{m}$ sieve. In this study, the (212) and (411) reflections were employed since they have strong relative intensity $\left(\mathrm{I} / \mathrm{I}_{0}\right)$ and are not close to other reflections. The mean crystallite size has been estimated by the Scherrer method using the expression:

$$
D=\frac{K \lambda}{B \cos \theta_{B}},
$$

where: $K$ it is a constant which depend of the crystal morphology, whether $K=1$ the mean crystallite size error approaches $\pm 10 \%$ [13]; $\mathrm{D}$ is the mean crystallite size; $\lambda$ is the wavelength; $B$ is difference between angle at the full-width at half-maximum (FWHM) of the XRD peak and; $\theta_{B}$ is the angle where the peak intensity is maximum.

\section{Results and Discussion}

Back-scattered electron images of the as-cast and annealed Pr-based alloys are shown in Figure 1 and Figure 2. It can be seen clearly that annealing at $1100^{\circ} \mathrm{C}$ for $20 \mathrm{~h}$ was quite effective in homogenizing the alloys. The dark phase ( $\mathrm{FeCo}$ ) was completely eliminated from the interior of the $\phi$ or matrix phase grains (dark grey phase). The 
Table 1. Composition of the as-cast Pr-based cast ingot alloys.

\begin{tabular}{ccccccc}
\hline \multirow{2}{*}{$\begin{array}{c}\text { Nominal composition } \\
\text { (at\%) }\end{array}$} & \multicolumn{7}{c}{ Analyzed composition (wt\%) } \\
\cline { 2 - 7 } & $\operatorname{Pr}^{\mathrm{a}}$ & $\mathrm{Fe}$ & $\mathrm{Co}$ & $\mathrm{B}$ & $\mathrm{Nb}$ & $\mathrm{M}$ \\
\hline $\mathrm{Pr}_{14} \mathrm{Fe}_{\text {bal }} \mathrm{Co}_{16} \mathrm{~B}_{6} \mathrm{Nb}_{0.1}$ & 30.35 & 54.11 & 14.34 & 0.96 & 0.14 & - \\
$\mathrm{Pr}_{14} \mathrm{Fe}_{\text {bal }} \mathrm{Co}_{16} \mathrm{~B}_{6} \mathrm{Nb}_{0.1} \mathrm{Cu}_{0.1}$ & 30.51 & 53.79 & 14.25 & 0.99 & 0.15 & 0.13 \\
\hline
\end{tabular}

${ }^{\mathrm{a}} \mathrm{Pr}+0.2$ - $0.7 \mathrm{wt} \% \mathrm{Nd} ;{ }^{+}$nominal composition: $0.05 \mathrm{wt} \%$.

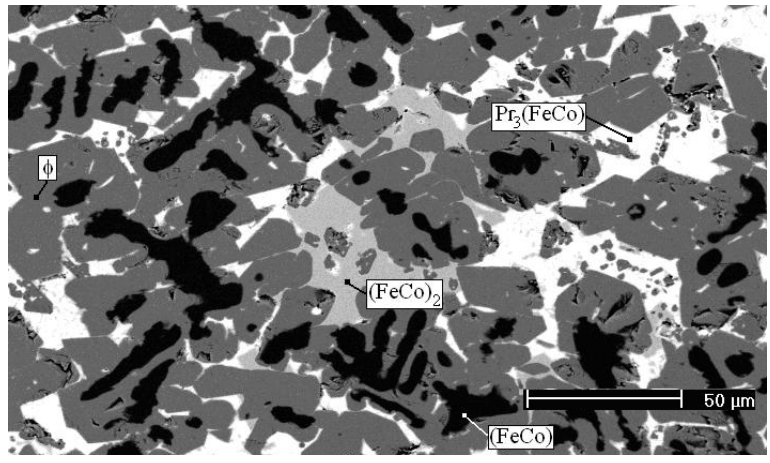

(a)

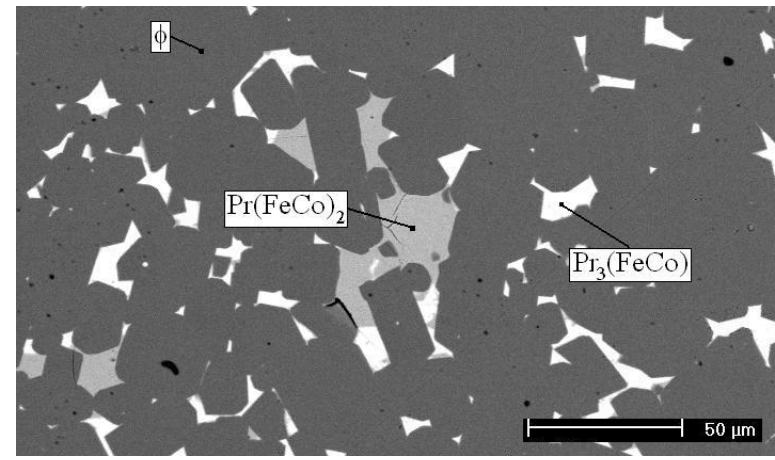

(b)

Figure 1. Backscattered electron image of the $\operatorname{Pr}_{14} \mathrm{Fe}_{\text {bal }} \mathrm{Co}_{16} \mathrm{~B}_{6} \mathrm{Nb}_{0.1}$ alloy in the (a) as cast and (b) homogenized condition.

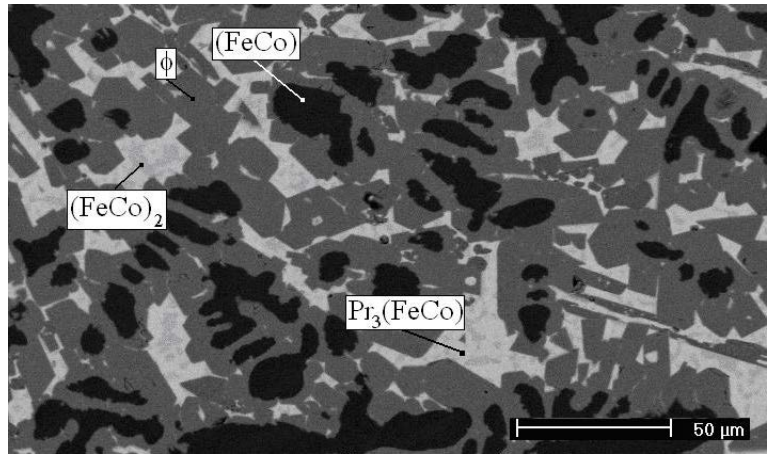

(a)

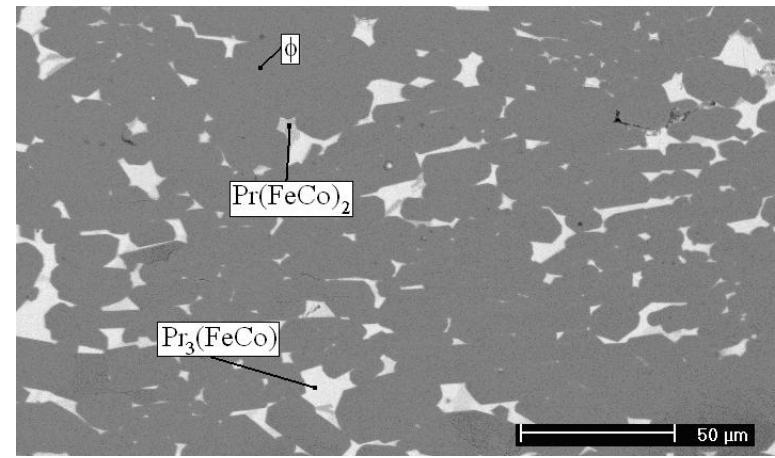

(b)

Figure 2. Backscattered electron image of the $\operatorname{Pr}_{14} \mathrm{Fe}_{\text {bal }} \mathrm{Co}_{16} \mathrm{~B}_{6} \mathrm{Nb}_{0.1} \mathrm{Cu}_{0.1}$ alloy in the (a) as cast and (b) homogenized condition.

grain boundary phases present in the as-cast alloys, $\operatorname{Pr}_{3}(\mathrm{FeCo})$ and $\operatorname{Pr}(\mathrm{FeCo})_{2}$, have also been detected and reported in a previous study [14]. Table 2 summarizes the magnetic properties and density of all the Pr-based bonded magnets prepared using these alloys in the annealed condition. The secondary electron image of the $\operatorname{Pr}_{14} \mathrm{Fe}_{\text {bal }} \mathrm{Co}_{16} \mathrm{~B}_{6} \mathrm{Nb}_{0.1}$ powder that yielded magnets with enhanced $B_{r}$ is shown in Figure 3(a). The grain size of the magnetic material prepared with this alloy varied roughly from 0.5 to about $1.5 \mu \mathrm{m}$. This secondary electron image is quite similar to that of $\mathrm{Nd}_{12.6} \mathrm{Fe}_{63.1} \mathrm{Co}_{17.4} \mathrm{Zr}_{0.1} \mathrm{Ga}_{0.3} \mathrm{~B}_{6.5}$ and $\mathrm{Pr}_{13.7} \mathrm{Fe}_{63.5} \mathrm{Co}_{16.7} \mathrm{~B}_{6} \mathrm{Zr}_{0.1}$ powder, which also yielded good bonded magnets [9] [15] [16].

The addition of copper to the $\operatorname{Pr}_{14} \mathrm{Fe}_{\text {bal }} \mathrm{Co}_{16} \mathrm{~B}_{6} \mathrm{Nb}_{0.1}$ alloy decreased $B_{r}$ slightly and was very deleterious in terms of ${ }_{i} H_{c}$. The secondary electron image of the material that yielded bonded magnets with inferior magnetic properties is shown in Figure 3(b). The grain size of the magnetic material prepared with this copper-containing alloy varied approximately from 1 to around $2 \mu \mathrm{m}$. This is consistent to the diminished ${ }_{i} H_{c}$ found with this material. The fracture surface of the $\operatorname{Pr}_{14} \mathrm{Fe}_{\text {bal }} \mathrm{Co}_{16} \mathrm{~B}_{6} \mathrm{Nb}_{0.1} \mathrm{Cu}_{0.1}$ pulverized material exhibited a very distinct secondary electron image compared to that of $\mathrm{Cu}$-free material (very different grain structure and size). Among several addition elements that have been investigated, $\mathrm{Cu}$ showed the lowest eutectic temperature when combined with $\operatorname{Pr}\left(461^{\circ} \mathrm{C}\right)$ [17]. Grain refinement in cast PrFeBCu-type alloy has been attributed to this element [18] but 
Table 2. Magnetic properties and density of the cyanoacrylate bonded magnet prepared with the alloy annealed at $1100^{\circ} \mathrm{C}$ for $20 \mathrm{~h}$ under high vaccum. Permeameter measurement at room temperature after saturation in a 6 T magnetic pulse field.

\begin{tabular}{ccccccc}
\hline Composition & $\mathrm{B}_{\mathrm{r}}(\mathrm{mT})$ & $\mu_{\mathrm{o} i \mathrm{c}} \mathrm{H}_{\mathrm{c}}(\mathrm{mT})$ & $\mu_{\mathrm{ob}} \mathrm{H}_{\mathrm{c}}(\mathrm{mT})$ & $(\mathrm{BH})_{\max }\left(\mathrm{kJ} / \mathrm{m}^{3}\right)$ & $\mathrm{SF}(\mathrm{ratio})$ & $\rho\left(\mathrm{g} / \mathrm{cm}^{3}\right)$ \\
\hline $\mathrm{Pr}_{14} \mathrm{Fe}_{\mathrm{bal}} \mathrm{Co}_{16} \mathrm{~B}_{6} \mathrm{Nb}_{0.1}$ & $660 \pm 10$ & $1080 \pm 20$ & $540 \pm 10$ & $70.0 \pm 1.6$ & $0.37 \pm 0.01$ & $5.31 \pm 0.01$ \\
$\mathrm{Pr}_{14} \mathrm{Fe}_{\mathrm{bal}} \mathrm{Co}_{16} \mathrm{~B}_{6} \mathrm{Nb}_{0.1} \mathrm{Cu}_{0.1}$ & $620 \pm 10$ & $780 \pm 20$ & $440 \pm 10$ & $54.0 \pm 1.1$ & $0.37 \pm 0.01$ & $5.24 \pm 0.01$ \\
\hline
\end{tabular}

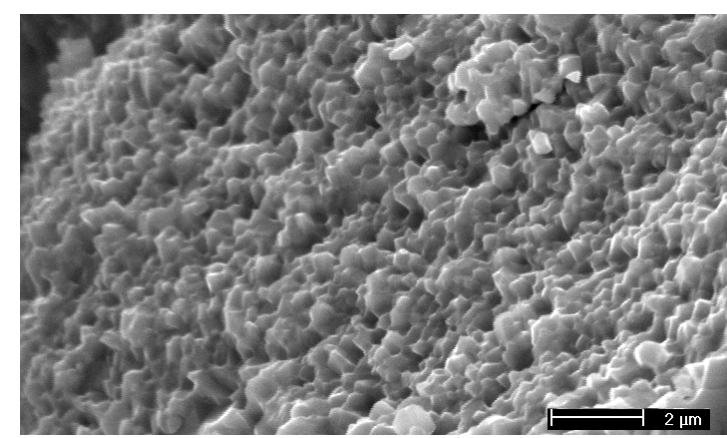

(a)

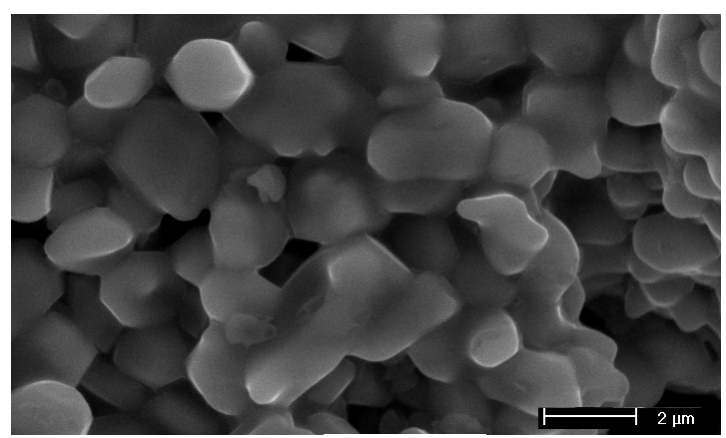

(b)

Figure 3. Secondary electron image of hydrogen processed material prepared from the homogenized alloy: (a) $\mathrm{Pr}_{14} \mathrm{Fe}_{\text {bal }} \mathrm{Co}_{16} \mathrm{~B}_{6} \mathrm{Nb}_{0.1}$; (b) $\mathrm{Pr}_{14} \mathrm{Fe}_{\text {bal }} \mathrm{Co}_{16} \mathrm{~B}_{6} \mathrm{Nb}_{0.1} \mathrm{Cu}_{0.1}$ (both: fracture surface; magnification 8000×; mark: $2 \mu \mathrm{m}$ ).

this has not been observed in the cast or annealed PrFeCoBNbCu alloys (comparison in Figure 1 and Figure 2), although in this investigation $\mathrm{Cu}$ had a substantial effect on the pulverized material. At first glance, it might be thought that the eutectic Cu-Pr phase with a low melting point would interfere on the hydrogen process at high temperature $\left(\sim 860^{\circ} \mathrm{C}\right)$. In this process, Pr elements should be tied up with hydrogen after completion of the hydrogenation-disproportionation stage. Therefore, the eutectic Pr-Cu phase may not be present to interfere on the hydrogen processing, at least, in a direct way.

$B_{r}$, on the other hand, is affected by the crystallographic alignment of the magnetically hard matrix phase grains. Local microtextural analysis using electron backscattered diffraction (EBSD) was carried out successfully on the sintered NdFeB magnets [19]. Attempts to use this technique on individual grains of the magnetic powder prepared in this investigation have been unsuccessful so far. Hence, the $B_{r}$ value is still the best indicator of anisotropy in the bonded magnets. This property of a magnet depends directly on the volume fraction (f) and saturation polarization $\left(\mathrm{I}_{\mathrm{s}}\right)$ of the hard magnetic phase $(\phi)$, as well as on the degree of easy-axis alignment of the single crystals $\phi$ grains $(<\cos \theta>)$ ) and magnet density. In the bonded magnets studied here, the volume fraction can be regarded as a constant, considering that the amount of element added is extremely low (0.1 at\%). The packing factor ( $\mathrm{P}=$ magnet density/theoretical density) for an ideal magnet is unity and in this investigation it has been normalized to this maximum value. Again, since the amount of element added is negligible, the spontaneous polarization of the Co-containing matrix phase can also be regarded as a constant. The degree of texture of the bonded magnets is also influenced by a possibility of inclusion of multigrain particles in the powders or not.

Figure 4 and Figure 5 show the (212) and (411) peaks analyzed to determine the mean crystallite size using the Scherrer method and synchrotron radiation. The mean crystallite size of the magnetic powder prepared with the two alloys varies from $0.62 \mu \mathrm{m}$ to $0.81 \mu \mathrm{m}$ (error $\pm 10 \%$ ). This range is more than two fold the well accepted value $(0.3 \mu \mathrm{m})$ for Nd-based HDDR material and might explain the slightly lower ${ }_{i} H_{c}$ observed in the Pr-based magnets. It is worth noting that the FWHM method gives only a rough estimate of the mean crystallite size. The XRD result for the magnetic material showed no significant contrast in the mean crystallite size with the presence of $\mathrm{Cu}$ in the alloy as the SEM observation of grain size and structure shown previously in Figure 3(a) and Figure 3(b). In the Scherrer method, mean crystallite size will be detected and it is likely that the result represented the average crystallite inside of the matrix phase grains. The XRD pattern shown in Figure 6 is typical for the magnetic material prepared with the $\operatorname{Pr}_{14} \mathrm{Fe}_{\text {bal }} \mathrm{Co}_{16} \mathrm{~B}_{6} \mathrm{Nb}_{0.1}$ and $\mathrm{Pr}_{14} \mathrm{Fe}_{63.8} \mathrm{Co}_{16} \mathrm{~B}_{6} \mathrm{Nb}_{0.1} \mathrm{Cu}_{0.1}$ alloy. No significant differences were found on the patterns of the material produced with the alloy containing $\mathrm{Cu}$.

It is well established that each particular composition requires its own set of processing parameters as the 


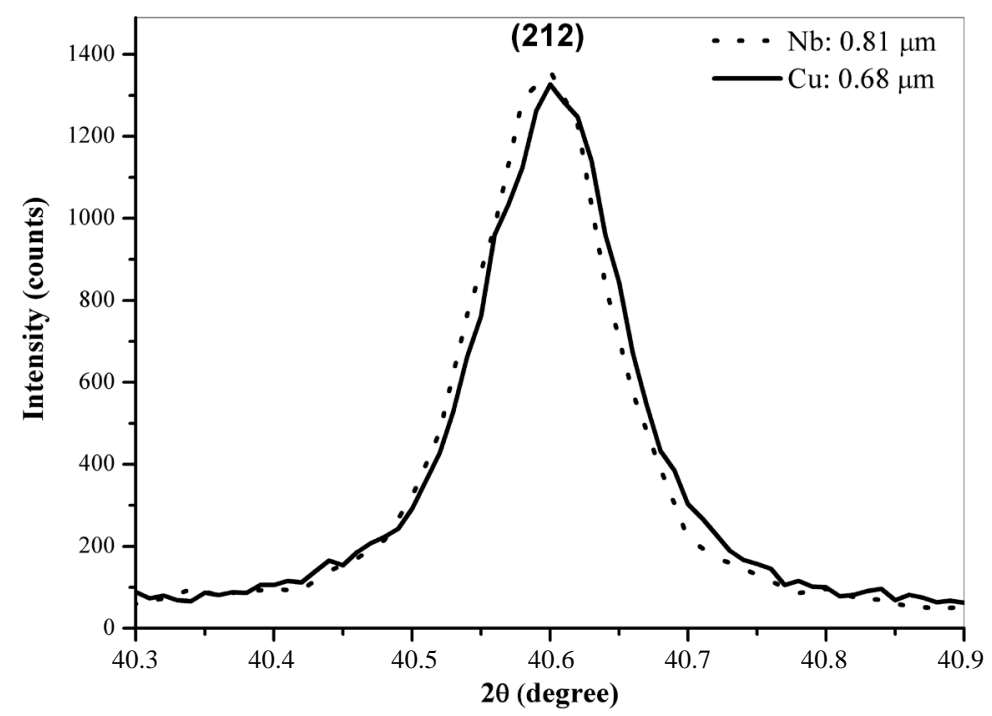

Figure 4. Close view of the (212) peaks and estimated mean crystallite size $(\mathrm{K}=1)$.

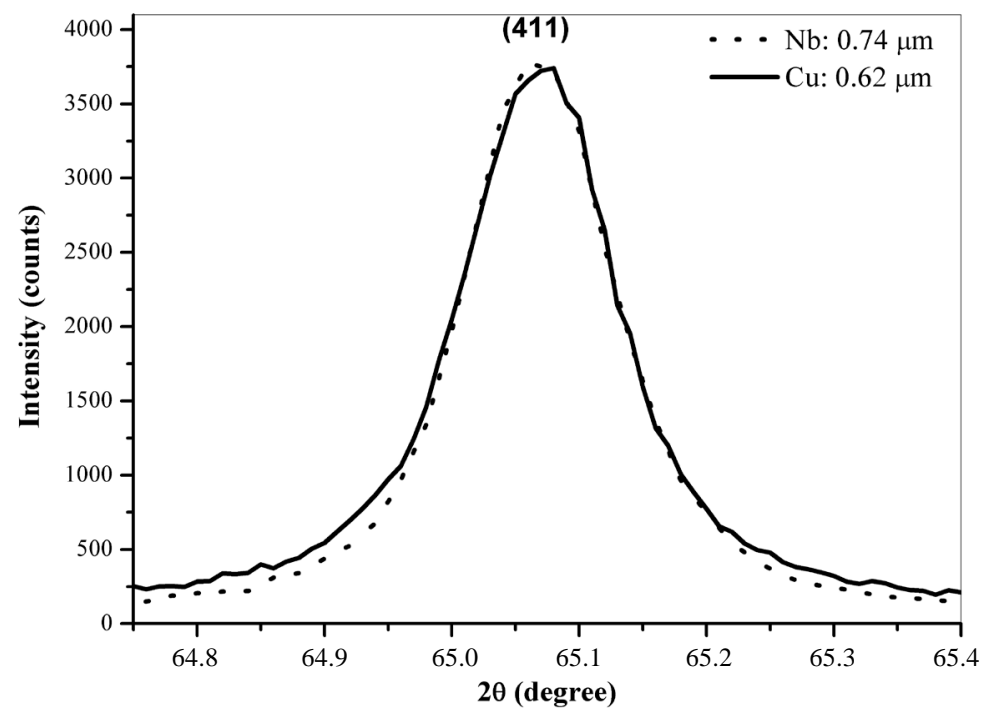

Figure 5. Close view of the (411) peaks and estimated mean crystallite size $(\mathrm{K}=1)$.

thermodynamic stability and microstructure of the parent compound is modified in a specific manner by the addition of a certain element. Cu addition affected slightly $B_{r}$ or degree of alignment. The "memory-cell” model suggests that nano-scale regions of the matrix phase containing the element that was added remained unaffected by the disproportionation reaction and act as nucleation sites during recombination [5] [20] [21].

Nevertheless, it is also known that anisotropy can be achieved by appropriate processing and for 2-14-1 compounds, without the addition of dopants. For Pr-based alloys $\left(\mathrm{Pr}_{13.7} \mathrm{Fe}_{63.5} \mathrm{Co}_{16.7} \mathrm{~B}_{6} \mathrm{Zr}_{0.1}\right.$ and $\left.\mathrm{Pr}_{13.7} \mathrm{Fe}_{80.3} \mathrm{~B}_{6}\right)$, it has been reported that the role of the Co and $\mathrm{Zr}$ additives is not primarily the stabilization of the 2-14-1 matrix phase against disproportionation but more importantly the stabilization of intermediate boride phases after disproportionation which could lead to an effective inducement of texture on recombination [22] [23].

It was reported that when $\mathrm{Cu}$ is added to REFeB-type alloys, it remains preferentially in the grain boundaries as a low melting point eutectic mixture with the rare earth [24]. Further, in $\mathrm{Cu}$-containing magnets, the $\mathrm{Cu}$ content in the $\mathrm{Pr}_{2} \mathrm{Fe}_{14} \mathrm{~B}$ matrix phase has been found to be negligible [24] or has not been observed in the matrix phase of Nd-based materials [25]. It has been reported that the solubility of $\mathrm{Cu}$ in the $\mathrm{Nd}_{2} \mathrm{Fe}_{14} \mathrm{~B}$ is below the res- 


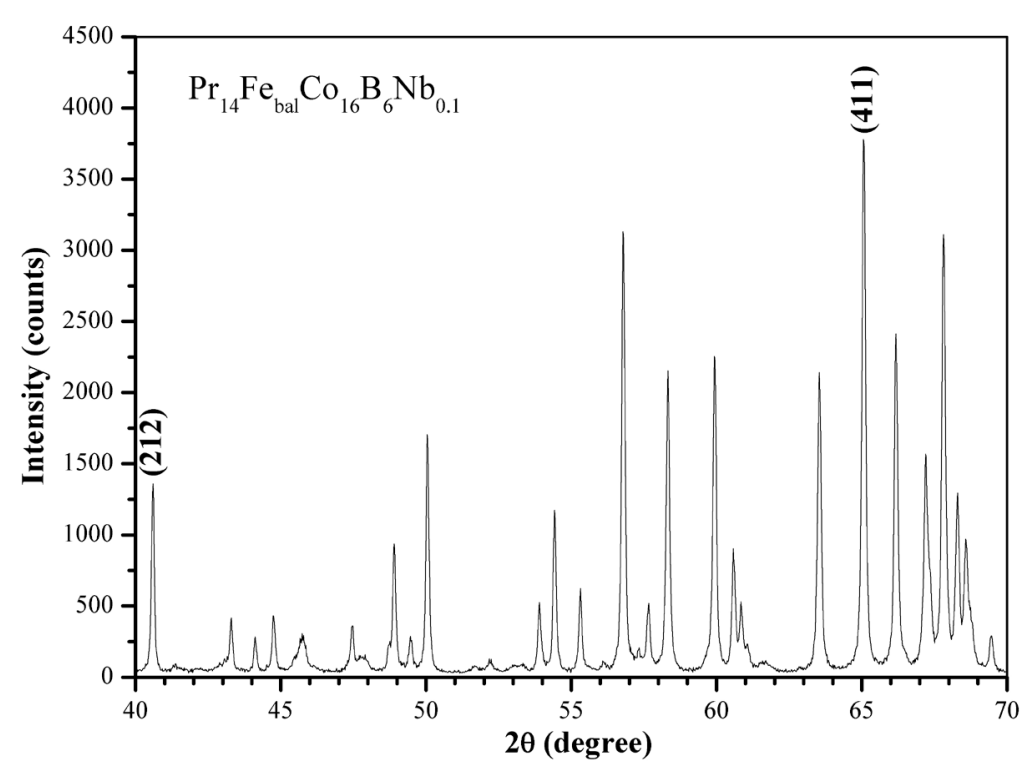

(a)

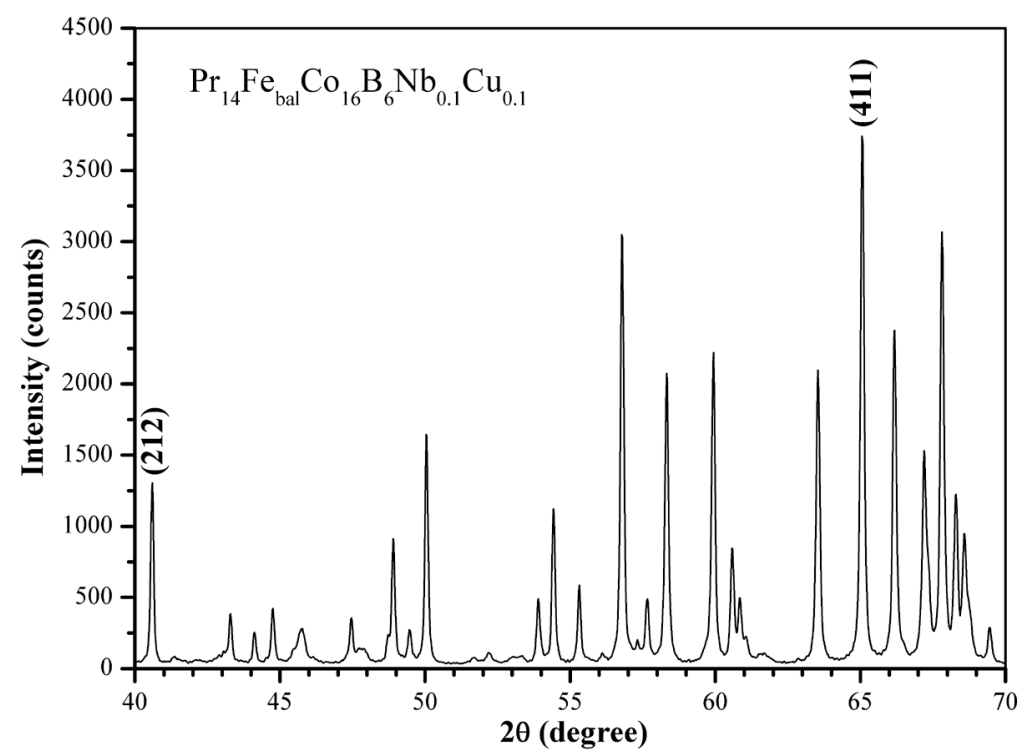

(b)

Figure 6. X-ray diffraction pattern of the hydrogen processed: $\mathrm{Pr}_{14} \mathrm{Fe}_{\text {bal }} \mathrm{Co}_{16} \mathrm{~B}_{6} \mathrm{Nb}_{0.1}$ (a); and $\mathrm{Pr}_{14} \mathrm{Fe}_{\text {bal }} \mathrm{Co}_{16} \mathrm{~B}_{6} \mathrm{Nb}_{0.1} \mathrm{Cu}_{0.1}$ (b) powder using monochromatic synchrotron radiation $(\mathrm{E}=5.412 \mathrm{keV})$.

olution of EDX and is about 1 at\% in the Nd-rich phase [26]. It might be thought that a matrix phase with few $\mathrm{Cu}$ nucleation centers would not maintain the c-axis orientation of the original large $\phi$ grain and would therefore yield an isotropic material. According to the previous studies [2] [9], this should not be the case because the present Pr-based alloy contains 16 atomic percent Co, which serves as the principal element to induce texture in the hydrogen processing. On the other hand, if a minimal amount of $\mathrm{Cu}$ inside the matrix phase were to provide sufficient nucleation sites, then there would not be sufficient thermodynamic stability to avoid the disproportionation reaction of the matrix phase. This also might not be the case for the present PrFeCoBNbM magnets since $\mathrm{Cu}$ is present in the matrix phase of the $\mathrm{Pr}_{14} \mathrm{Fe}_{\text {bal }} \mathrm{Co}_{16} \mathrm{~B}_{6} \mathrm{Nb}_{0.1} \mathrm{Cu}_{0.1}$ alloy in about 0.3 at\% (because $\mathrm{B}$ could not be determined by EDX analysis the $\mathrm{Cu}$ content should be higher than this value [27]). If the base alloys did not contain other elements than the principal elements (Pr, Fe and B), the latter argument on the effects of very small amount of $\mathrm{Cu}$ addition might have sense, but the effects of $\mathrm{Cu}$ in such a small amount should be over- 
whelmed by the effects of Co and also by Pr.

Previous work has shown that increase in $\mathrm{Nb}$ content from 0.1 to 0.5 at $\%$ decreases the $B_{r}$ of the magnets [28]. Increases in the amount of $\mathrm{Cu}$ to $0.5 \mathrm{at} \%$ also decreased the $B_{r}$ of the magnets prepared in this investigation. In this case, $\mathrm{Cu}$ content, also determined by EDX, in the alloy matrix phase were slightly higher. This indicates that only small amounts of these elements are necessary to induce anisotropy, or the right amount of alloying addition is necessary for achieving high anisotropy. It is possible that the addition of large amounts of any element will create a large number of non-disproportionated regions and dilute the matrix phase with the appearance of new phases. The effect of Ti, $\mathrm{V}, \mathrm{Cr}, \mathrm{Mo}, \mathrm{Al}, \mathrm{Si}$ and $\mathrm{P}$ additions on the magnetic properties of bonded magnets have also been reported previously [29].

\section{Conclusions}

The mean crystallite size determined using synchrotron diffractometry and the Scherrer method were consistent for both (212) and (411) reflections. No significant difference has been found in the mean crystallite size with $\mathrm{Cu}$ addition with this method. For both alloys the mean crystallite size of the magnetic powder estimated by this method varied from $0.62 \pm 0.06 \mu \mathrm{m}$ to $0.81 \pm 0.08 \mu \mathrm{m}$. Scanning electron microscopy clearly showed a distinct variation on the grain structure and size with $\mathrm{Cu}$ addition. Typical secondary electron images of the $\mathrm{Pr}_{14} \mathrm{Fe}_{\text {bal }} \mathrm{Co}_{16} \mathrm{~B}_{6} \mathrm{Nb}_{0.1}$ magnetic powder, that yielded bonded magnets with good magnetic properties, were quite distinct to that of the $\mathrm{Pr}_{14} \mathrm{Fe}_{\text {bal }} \mathrm{Co}_{16} \mathrm{~B}_{6} \mathrm{Nb}_{0.1} \mathrm{Cu}_{0.1}$ material. It has been also shown that the ${ }_{i} H_{c}$ of the $\mathrm{Pr}$-based magnets decreased considerably with $\mathrm{Cu}$ addition and this addition yielded larger $\phi$ grains. It has been inferred that the effect of such a small amount of $\mathrm{Cu}$ should not be that of thermodynamics but might be a kinetic effect localized in the vicinity of the reaction front. In the $\mathrm{Cu}$-free powder the $\phi$ grains should be constituted by one crystallite whereas in the Cu-containing two crystallites could be inside the $\phi$ grains. Scanning electron microscopy and synchrotron diffractometry can be complementary in investigations of high temperature hydrogen processed magnetic powders. The former is appropriate for grain morphology (structure/size) and the latter for estimation of the mean crystallite size inside the grains.

\section{Acknowledgements}

The authors wish to thank FAPESP and IPEN-CNEN/SP for the financial support and infrastructure made available to carry out this investigation. We also would like to thank the XPD Beamline staff for the help during the experiment at the National Synchrotron Light Laboratory (LNLS), Brazil.

\section{References}

[1] Hirosawa, S., Uehara, M., Mino, S., Ishigaki, N. and Tomida, T. (1997) New Aspects of Nd-Fe-B-Based Hydrogenation-Disproportionation-Desorption-Recombination Powders and Anisotropic Bonded Magnets Made from Them: Microstructure and Magnetic Properties. Journal of Applied Physics, 81, 4821-4826. http://dx.doi.org/10.1063/1.365472

[2] Gutfleish, O. and Harris, I.R. (1998) Hydrogen Assisted Processing of Rare-Earth Permanent Magnets. Fifteenth International Workshop on Rare-Earth Magnets and Their Applications, Dresden, September 1998, 487.

[3] Nakayama, R., Takeshita, T., Itakura, M., Kuwano, N. and Oki, K. (1991) Magnetic-Properties and Microstructures of The Nd-Fe-B Magnet Powder Produced by Hydrogen Treatment. Journal of Applied Physics, 70, 3770-3774. http://dx.doi.org/10.1063/1.349232

[4] Nakayama, R., Takeshita, T., Itakura, M., Kuwano, N. and Oki, K. (1994) Microstructures and Crystallographic Orientation Of Crystalline Grains in Anisotropic Nd-Fe-Co-B-(Ga or Zr) Magnet Powders Produced by the HydrogenationDecomposition-Desorption-Recombination Process. Journal of Applied Physics, 76, 412-417. http://dx.doi.org/10.1063/1.349232

[5] Nakayama, R. and Takeshita, T. (1993) Nd-Fe-B Anisotropic Magnet Powders Produced by the HDDR Process. Journal of Magnetism and Magnetic Materials, 193, 259.

[6] Takeshita, T. and Marimoto, K. (1996) Anisotropic Nd-Fe-B Bonded Magnets Made from HDDR Powders. Journal Applied Physics, 79, 5040-5044. http://dx.doi.org/10.1063/1.361567

[7] Pan, W., Cui, L.Y., Wang, P. and Zhou, S.X. (1996) Magnetic Properties of HDDR Processed $\left(\operatorname{Pr}_{1-x} N_{x}\right)_{13} F_{81} B_{6}$. Fourteenth International Workshop on Rare-Earth Magnets and Their Applications, São Paulo, 467.

[8] Kim, Y.B. and Jeung, W.Y. (1998) Hydrogen Absorption and Desorption Behavior in Pr-Fe-B Type Alloys. Journal of Applied Physics, 83, 6405-6407. http://dx.doi.org/10.1063/1.367920 
[9] Faria R.N., Davies, B.E., Brown, D.N. and Harris, I.R. (2000) Microstructural and Magnetic Studies ff Cast and Annealed Nd and PrFeCoBZr Alloys and HDDR Materials. Journal of Alloys and Compounds, 296, 223-228. http://dx.doi.org/10.1016/S0925-8388(99)00536-8

[10] Shimoda, T., Akioka, K., Kobayashi, O. and Yamagami, T. (1988) High-Energy Cast Pr-Fe-B Magnets. Journal of Applied Physics, 64, 5290-5292. http://dx.doi.org/10.1063/1.342395

[11] Shimoda, T., Akioka, K., Kobayashi, O. and Yamagami, T. (1990) Development of Hot-Rolled R-Fe-B Magnets. Eleventh International Workshop on Rare Earth Magnets and Their Applications, Pittsburg, 1990, 17.

[12] Faria, R.N., Abbel, J.S. and Harris, I.R. (1991) High Coercivity Sintered Pr-Fe-B-Cu Magnets Using the Hydrogen Decrepitation Process. Journal of Alloys and Compounds, 177, 311-320. http://dx.doi.org/10.1016/0925-8388(91)90084-9

[13] Azároff, L.V. and Bueguer, M.J. (1958) The Powder Method in X-Ray Crystallography. McGraw-Hill, New York.

[14] Barbosa, L.P., Takiishi H. and Faria, R.N. (2004) The Effect of Cobalt Content on the Microstructure of Pr-Fe-Co-B$\mathrm{Nb}$ Alloys and Magnetic Properties Of HDDR Magnets. Journal of Magnetism and Magnetic Materials, 268, 132-139. http://dx.doi.org/10.1016/S0304-8853(03)00487-6

[15] Kawashita, Y., Waki, N., Tayu, T., Sugiyama, T., Ono, H., Koyama, H., Kanno, H. and Uchida, T. (2003) Microstructures and Magnetic Properties of Hydrogenation Disproportionation Desorption Recombination-Processed Nd-Fe-B Materials with Different Nd Content of 11.0 and 12.6 at.\%. Journal of Alloys and Compounds, 360, 322-329. http://dx.doi.org/10.1016/S0925-8388(03)00504-8

[16] Cannesan, N., Brown, D.N., Williams, A.J. and Harris, I.R. (2001) The Production and Characterisation of Highly Anisotropic PrFeCob-Type HDDR Powders. Journal of Magnetism and Magnetic Materials, 233, 209-218. http://dx.doi.org/10.1016/S0304-8853(01)00212-8

[17] Takahashi, N., Nakamura, H., Paik, C.R., Sugimoto, S., Okada, M. and Homma, M. (1991) Coercivity and Microstructures in Pr-Fe-B-M Cast Alloys (M = Cu/Ga/Ag/Al/In/Pb). Materials Transactions JIM, 32, 90-92.

[18] Shimoda, T., Akioka, K., Kobayashi, O., Yamagami, T., Ohki, T., Miyagawa, M. and Yuri, T. (1989) Hot-Working Behavior of Cast Pr-Fe-B Magnets. IEEE Transactions on Magnetics, 25, 4099-4104. http://dx.doi.org/10.1109/20.42535

[19] Khlopkov, K., Gutfleisch, O., Eckert, D., Hintz, D., Wall, B., Rodewald, W., Muller K.H. and Schultz, L. (2004) Local Texture in Nd-Fe-B Sintered Magnets with Maximized Energy Density. Journal of Alloys and Compounds, 365, 259265. http://dx.doi.org/10.1016/S0925-8388(03)00636-4

[20] Harris, I.R. (1992) The Use of Hydrogen in the Production of Nd-Fe-B-Type Magnets and in the Assessment of Nd-Fe-B-Type Alloys and Permanent Magnets. Proceedings of 12th International Workshop on RE Magnets and their Applications, Camberra, 347.

[21] Uehara, M., Tomizawa H. and Hirosawa, S. (1993) Origin of Anisotropy in the HDDR Process of $\mathrm{Nd}_{2} \mathrm{Fe}_{14} \mathrm{~B}-\mathrm{Based}$ Alloys, IEEE Transactions on Magnetics, 29, 2770-2772. http://dx.doi.org/10.1109/20.281023

[22] Gutfleisch, O., Teresiak, A., Gebel, B., Muller, K.H., Cannesan, N.B., Brown, D. and Harris, I.R. (2001) Metastable Borides and the Inducement of Texture in $\mathrm{Pr}_{2} \mathrm{Fe}_{14} \mathrm{~B}$-Type Magnets Produced by HDDR. IEEE Transactions on Magnetics, 37, 2471-2473. http://dx.doi.org/10.1109/20.951206

[23] Cannesan, N., LeBreton, J.M., Williams, A.J. and Harris, I.R. (2002) The Evolution of the Disproportionated Microstructure of PrFeB-Based Alloys. Journal of Magnetism and Magnetic Materials, 242, 1372-1374. http://dx.doi.org/10.1016/S0304-8853(01)01236-7

[24] Kwon, H. W., Bowen, P. and Harris, I.R. (1991) Microstructural and Magnetic Studies on Pr-Fe-B-Cu Alloys. Journal of Applied Physics, 70, 6357-6359. http://dx.doi.org/10.1063/1.349941

[25] Kianvash, A. and Harris, I.R. (1992) The Effect of Heat-Treatment on the Microstructure and Magnetic-Properties of Sintered Magnets Produced From Nd-Fe-B Based Alloys with and without Cu Substitution. Journal of Alloys and Compounds, 178, 325-341. http://dx.doi.org/10.1016/0925-8388(92)90274-D

[26] Knoch, K.G., A. Kianvash, A. and Harris, I.R. (1992) Nd-Fe-B-Cu HD-Processed Sintered Magnets-Properties and Microstructure. IEEE Transactions on Magnetics, 28, 2142-2144. http://dx.doi.org/10.1109/20.179423

[27] Faria, R.N., Takiishi, H., Castro, A.R.M., Lima, L.F.C.P. and Costa, I. (2002) Chemical Microanalysis of Rare-EarthTransition Metal-Boron Alloys and Magnets Using Scanning Electron Microscopy. Journal of Magnetism and Magnetic Materials, 246, 351-359. http://dx.doi.org/10.1016/S0304-8853(02)00105-1

[28] Barbosa, L.P., Takiishi, H., Lima, L.F.C.P. and Faria, R.N. (2004) The Effect of Niobium Content on the Magnetic Properties and Microstructures of PrFeCoBNb HDDR Magnets and Alloys. Journal of Magnetism and Magnetic Materials, 283, 263-269. http://dx.doi.org/10.1016/j.jmmm.2004.05.032

[29] Galego, E., Takiishi, H. and Faria, R.N. (2007) Magnetic Properties of Pr-Fe-Co-B Bonded HDDR Magnets with Alloying Additions. Materials Research, 10, 273-277. http://dx.doi.org/10.1590/S1516-14392007000300010 
Scientific Research Publishing (SCIRP) is one of the largest Open Access journal publishers. It is currently publishing more than 200 open access, online, peer-reviewed journals covering a wide range of academic disciplines. SCIRP serves the worldwide academic communities and contributes to the progress and application of science with its publication.

Other selected journals from SCIRP are listed as below. Submit your manuscript to us via either submit@scirp.org or Online Submission Portal.
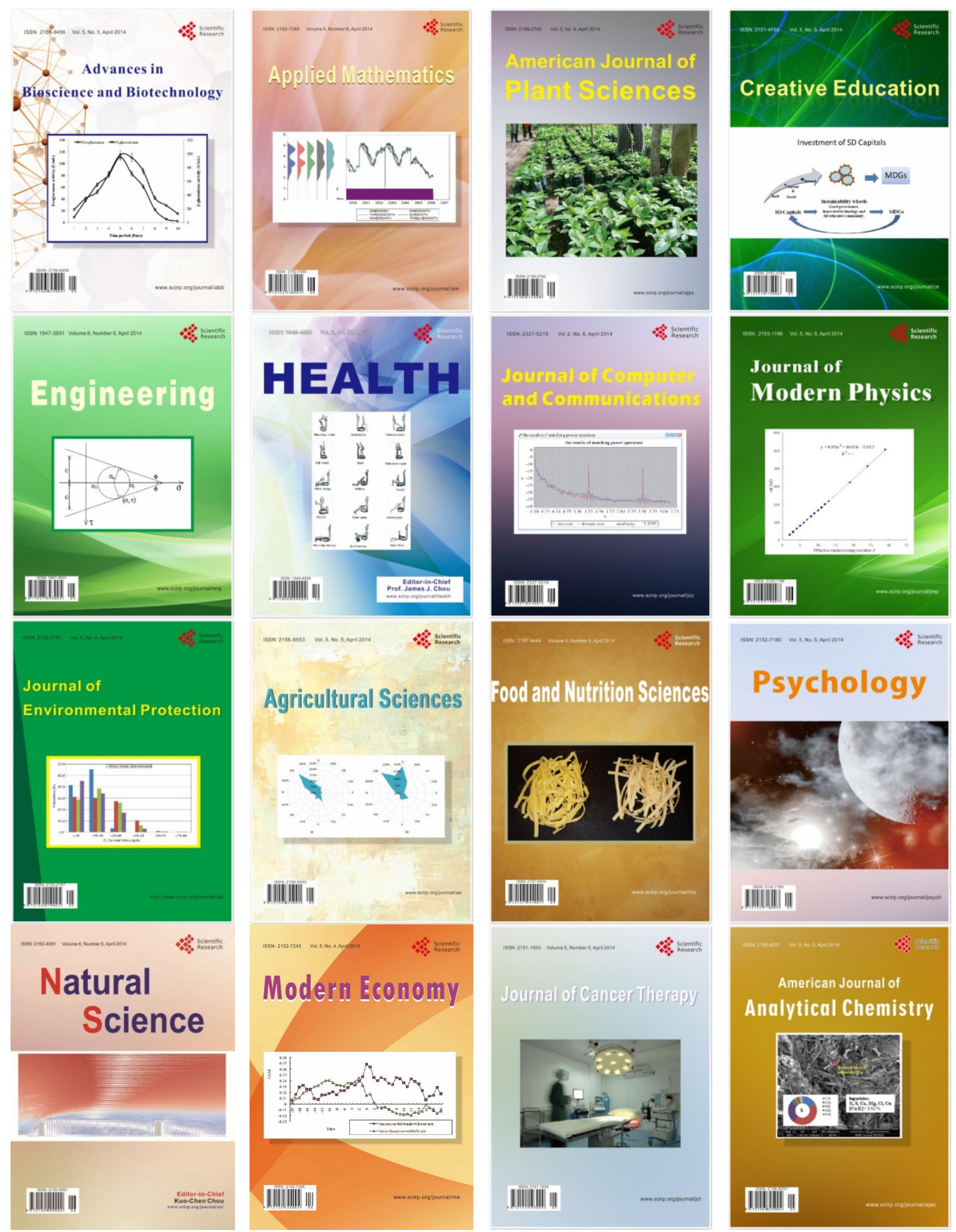